\title{
Introducción a la novela colombiana
}

\author{
A. Fuentes y Bibliografía
}

$\mathbf{H}$ AST $\Lambda$ ahora es relativamente poco lo que se ha publicado acerca de la novela colombiana. Parece que sólo hay una monografía sobre ella; ésta es La novela en Colombia, una tesis doctoral de Roberto Cortázar, escrita bajo la dirección de Antonio Gómez Restrepo (1869-1948), uno de los más respetados críticos colombianos de nuestra época. Como tal monografía aparece fechada en 1908, su valor - habida cuenta de los cuarenta y más años corridos desde entonces- no es muy grande, y sirve ahora principalmente para comprobar la bibliografía que se encuentra en cualquicra otra parte. ${ }^{1}$ Para mayor información, el investigador tiene que consultar obras más generales, historias de la literatura, y los prólogos de algunos volúmenes de la Selección Samper Ortega. ${ }^{2}$ Inevitablemente hay que actudir al formidable volumen de José J. Ortega T., Historia de la literatura colombiana; ${ }^{3}$ al Resumen de historia de la literatura co: lombiana, de Gustavo Otero Muñoz, ${ }^{4}$ muy útil a pesar de la brevedad del capítulo sobre la novela; al Panorama de la literatura colombiana de Nicolás Bayona Posada; ${ }^{5}$ y al volumen de Javier Arango Ferrer ya nombrado, el mejor de todos los mencionados, en cuanto a la novela se refiere. Infortunadamente, como los demás comentadores colombianos de la materia, Arango Ferrer estudia la novela con excesiva brevedad; junto con el del teatro, al estudio de la novela sólo se le dedican treinta páginas de su pequeño pero sustancioso trabajo. Novelistas buenos y malos, del P. Pablo Ladrón de Gueva$\mathrm{raj}^{6}$ volumen que durante mucho tiempo sirvió de patta a los confesores, es útil para comparar nombres y títulos - aunque no se des- 
taca por su exactitud-- y por cuanto, ocasionalmente, trae el resumen de alguna novela. Su crítica carece de valor objetivo, como que los novelistas y sus obras aparecen clasificados como buenos o malos según el criterio teológico y ético de los jesuítas. Necesariamente reducidos son los datos que nos proporciona Baldomero Sanín Cano en Letras colombianas, ${ }^{\top}$ y en su obra monumental sobre la Historia de la literatura colombiana, Antonio Gómez Restrepo no alcanzó a estudiar la novela. ${ }^{8}$

Tres conocidos críticos de otros países hispanoamericanos han manifestado un interés especial en la novela colombiana: Mariano Latorre, en "Primera glosa sobre la novela americana"; Alejandro Andrade Coello, en Algo sobre la novela en la América del Sur; ${ }^{10}$ y Ricardo A. Latcham, en "Perspectivas de la novela colombiana actual." 11 Referencias al penetrante ensayo de Latorre abundan en éste, y en la Bibliografía citamos tanto a Latorre como a Latcham siempre que se ocupen de las obras en ella incluídas. Escrito para el centenario de Isaacs, el opúsculo de Andrade Coello versa principalmente sobre María, siendo lo demás, con raras excepciones, poco más o menos un catálogo nada selecto de autores y obras.

Con respecto a la crítica hecha de la novela colombiana en países no de lengua española, quizá no vaya a sorprender grandemente el hecho de que Daniel S. Wogan no encontró nada en el Brasil de 1877 a 1925 , ni en forma de libro ni en cien publicaciones periódicas examinadas. Y de 1925 a 1944, sólo dió con menos de diez. artículos, inclusive necrologías, sobre Isaacs, Rivera, Carrasquilla y Vargas Vila, y con traducciones al portugués de no más que tres novelas - Maria, La vorágine, e Ibis (de Vargas Vila). ${ }^{12}$ El interés del norteamericano en la novela colombiana se limitaba, hasta dentro de los últimos diez años por lo menos, a la traducción de alguna que otra novela, o trozo de novela, y a la preparación de varias ediciones escolares de María. Lo demás eran breves reseñas y unos ensayos de índole general. ${ }^{13}$

Fuentes primeramente biográficas y bibliográficas que hemos consultado con provecho, son: Isidoro Laverde Amaya, Bibliografía colombiana; ${ }^{14}$ Luis Eduardo Nieto Caballero, Libros colombianos publicados en 1924 ; ${ }^{15}$ Joaquín Ospina, Diccionario biográfico y bibliográfico de Colombia; ${ }^{10}$ Libros colombianos, segunda serie; ${ }^{17}$ Libros colombianos, tercera serie ; ${ }^{18}$ Sturgis E. Leavitt y Carlos Gar- 
cía-Prada, A Tentative Bibliography of Colombian Literature; ${ }^{19} \mathrm{el}$ Handbook of Latin American Studies; ${ }^{20}$ Frederick Bliss Luquiens, Spanish American Literature in the Yale University Library; ${ }^{21} \mathrm{y}$ Gustavo Perry Zubieta, Quién es quién en Colombia. ${ }^{22}$

\section{B. LA NOVEla colombiana}

En poco más de cien años, unos doscientos cincuenta escritores han cultivado la novela en Colombia. Stus esfuerzos han dado como resultado un total de casi quinientas obras, inclusive varios títulos que bien podrían ser clasificados de novela corta, si no de novela. Hay que admitir que muchas de esas novelas son inferiores, y que seguramente menos de la mitad, o un número mayor aún, sobrevivirá sólo en los archivos del historiador literario como prueba de los esfuerzos de la joven república por alcanzar un puesto en el mundo de la cultura. Pero en términos generales la novela de Colombia puede parangonarse favorablemente con la de cualquier país de la América del Sur, y sus mejores manifestaciones son eminentemente dignas de lectura.

No sería aconsejable, ni es necesario, examinar todas las novelas y sus autores. Tampoco sería posible aquí hacer de la mayoría más que una mención breve. Así, las pocas novelas que aparecieron en primer término se encuentran aquí fuera de discusión, y son mencionadas sólo por los historiadores literarios. Las primeras son Maria Dolores, de José Joaquín Ortiz, publicada en Bogotá en 1841 pero escrita en Anapoima en 1836; Yngermina o la hija de Calamar de Juan José Nieto (Kingston, Jamaica, 1844) ; El oidor (Bogotá, 1848) de José Antonio de Plaza, relato novelesco de los amores del funcionario español Cortés de Mesa con doña María de Ocando; y El doctor Temis (Bogotá, 1851), de José María Angel Gaitán. Felipe Pérez comenzó a publicar en Bogotá, allá por 1850, una serie de novelas históricas que aún aparecían hacia el año 90. Algunas de ellas son: Huayna-Cápac y Atahualpa (1856), Los Pizarros (1857) y su secuela Jilma (1858), Carlota Corday (1881), El caballero de Ranzán (1887). Raimundo Bernal Orjuela publicó en Bogotá, en 1858, su Viene por mí i carga con usted, una "travesura histórico-novelesca de un curioso desocupado," según el propio autor. 
Otro contemporáneo de Felipe Pérez que se puso a cultivar la novela histórica fué Temístocles Avella Mendoza, autor de las novelas cortas Los tres Pedros (1864) y Anacoana (1865), entre otras, que en febrero de 1862 definió así su concepto de la novela histórica: "Si, pues, se pide fidelidad a la historia, concédase a la novela su ficción y disfraz, conservando sí, en éste y aquélla, la verosimilitud." En 1864 había aparecido en el periódico político La opinión (Bogotá), una novela titulada Una taza de claveles, posteriormente (1881) publicada en Bogotá como Los claveles de Julia. Su autor fué José María Samper, uno de los más destacados literatos colombianos. Los claveles de Julia no es, en modo alguno, una gran novela, pero ofrece una grata sorpresa gracias a su hábil trama sentimental, y a la maestría con que en ella se combinan lo romántico y lo realista. Sorprende también agradablemente su humor, una cualidad que no se encuentra muy a menudo en la novela colombiana.

Fué hacia 1860 cuando la más destacada novelista colombiana empezó a cultivar el género. Doña Soledad Acosta de Samper fué la esposa de don José María, y autora de numerosas novelas y cuentos. Su primera obra imaginativa de importancia fué Novelas $y$ cuadernos de la vida suramericana (Gante, 1869). Destacóse ante todo en el cultivo de la novela histórica y de costumbres, sirviéndole de modelos ahora Walter Scott, ahora Pérez Galdós. En el afán de novelizar la historia de su país, dejó, según Otero Muñoz, “. . la más ambiciosa empresa novelística que hayamos tenido." ${ }^{23}$ Se acepta generalmente que ninguna de sus producciones novelísticas sobrepasa el límite de la mediocridad en comparación con lo mejor que se ha escrito en Colombia.

En 1866 apareció en Bogotá una novela de la cual se enorgullecen los colombianos, y .con razón. Fué Manuela. Su autor fué Eugenio Díaz Castro. La labor de Díaz como novelista produjo algunos títulos adicionales, aunque menos famosos: El rejo de enlazar, Los aguinaldos en Chapinero, Pioquinta o el valle de Tena, Bruna la carbonera, y otros. De Manuela puede afirmarse con entera seguridad que tiene muchos de los elementos de una buena novela: caracterización adecuada, realista y ampliamente sostenida (aunque los personajes son muchos), un relato intrínsecamente interesante, y espléndida descripción de costumbres. El argumento es simple y la novela difusa, buena para una época más ociosa que la nuestra, 
lo que explica el hecho de que la lentitud de su desarrollo impaciente al lector moderno. La narración se interrumpe a veces para dar paso a las digresiones del autor sobre temas más o menos ajenos al principal. Es posible que no haya otro documento que ofrezca una descripción más clara del sistema de vida de los campesinos de la zona en que se desarrolla la acción; la obra tiene el subtítulo de Una novela de costumbres colombianas. Se habla francamente del caos político de la época; el autor, de filiación política conservadora, presenta como protagonista a un caballero de Bogotá, don Demóstenes, para satirizar su liberalismo político. El "gamonalismo," tremendo azote del sector septentrional de la América del Sur aun en nuestros días, es una fuerza directriz de la novela. Manuela es una hermosa negra de una anónima aldea de la vertiente este de la cordillera oriental no lejos de Bogotá y del río Magdalena. Rechaza al villano gamonal don Tadeo quien, para vengarse, la hace encarcelar por un falso cargo. Es libertada mediante los esfuerzos de don Demóstenes, quien se interesa platónicamente por ella. Aquél logra arreglar su matrimonio con un joven de la vecindad, pero el artero don Tadeo los persigue hasta el fin. Manuela muere a causa de las quemaduras que recibe cuando don Tadeo prende fuego a la iglesia en que ella y su novio están uniéndose en matrimonio.

Dos de las más famosas novelas colombianas aparecieron con un año de diferencia, pues fué en 1867 cuando Jorge Isaacs publicó su María, y ya hemos visto que Manuela apareció el año anterior. Sobre Maria -que habrá pasado por más ediciones que ninguna otra novela hispanoamericana- se ha escrito más que sobre cualquier novela colombiana y acaso de toda la América latina. Transcu- rrirían dos décadas antes de que apareciera otra novela que pasara las fronteras nacionales. Fué en el mismo año de 1886 cuando Eustaquio Palacios publicó su novela histórica caleña, El alférez real y Luis Segundo de Silvestre la superior novela de costumbres, Tránsito, que Otero Muñoz no vacila en aclamar "de lo mejor que tenemos", y por consiguiente, merecedora "de ser más leída entre nosotros ..." Aunque no tan universalmente conocidas como la novela de Isaacs, en los Estados Unidos por lo menos han conseguido alcanzar ediciones especiales y juntamente con Maria han llegado a las manos de la juventud estudiantil. Sobra aquí, pues, hablar más de ninguno de estos tres buenos mensajeros de la prosa amena de Colombia. 
El año de 1896 presenció la aparición de una de las mejores novelas colombianas, y la iniciación en el arte novelístico de uno de los mejores cuentistas del país. La novela fué Frutos de mi tie$r r a$; su autor, Tomás Carrasquilla, el antioqueño. ${ }^{24}$ Carrasquilla merece espacio mayor que el que aquí se le concede. Sus obras mejor logradas le asignan un puesto al lado de los más destacados novelistas latinoamericanos. Mariano Latorre lo compara con Blest Gana: ambos son verdaderos gigantes de la novela americana. Ambos nacieron en un medio demasiado estrecho para sus aptitudes, y ambos rebasaron esos límites a fuerza de consumada maestría. La habilidad de Carrasquilla en la caracterización trae inevitablemente a la memoria la de Pereda; la simpatía sensitiva con que describe las costumbres apaciblemente dramáticas de la región; su tranquilo pero auténtico humor; su capacidad para pintar lo feo y lo cruel como debilidades de la naturaleza humana, sin caer, sin embargo, en la morbosidad, la pornografía o la vulgaridad, y su igualmente positiva capacidad de descubrir y describir lo noble del corazón, todo ello hace de él una figura verdaderamente excepcional de las letras americanas. Tiene sus faltas, desde luego. A veces el relato vacila; ocasionalmente flaquean sus caracterizaciones; a menudo divaga y cae en la verbosidad. Pero estos defectos aparecen compensados por su enorme habilidad en el manejo del diálogo y por la exactitud con que reproduce el habla arcaica y característica de la región. Otra aparente debilidad ha resultado un elemento de fuerza: el carácter local de sus novelas. Como regionalista se atuvo primordialmente a lo que conocía, y como sus observaciones son las de un individuo de excepcionales dotes, el resultado ha sido una gema geográfica pequeña pero primorosamente tallada.

Para el lector de Frutos de mi tierra y La Marquesa de Yolombó, obras ampliamente representativas de su arte, Carrasquilla ha de ser, descontadas pequeñas fallas de su maestría de narrador, uno de los más amenos novelistas. Ambas novelas son para adultos. Los relatos de Carrasquilla carecen de esa puerilidad infortunadamente demasiado común en las obras imaginativas latinoamericanas. Frutos de mi tierra es un cuadro de costumbres de Medellín del último cuarto del siglo xIx. El aspecto principal del relato se refiere a un hermano y tres hermanas que viven juntos después de la muerte de sus padres. El hermano y una hermana son astutamente ines- 
crupulosos; las hermanas restantes son generosas, buenas y excesivamente ingenuas para sospechar la bellaquería de los dos primeros. Al hermano le dan públicamente de latigazos por calumniador; el castigo le produce un colapso espiritual que lo reduce al lecho y no 1c deja recobrar la salud. Después de cierto tiempo es incapaz de dirigir los negocios que posee en compañia de Filomena, la hermana dominadora. Ella, enfrentada a la perspectiva de atender a sus extensos negocios, acepta la ayuda de un sobrino, hijo de una cuarta hermana, que se ha casado muy joven y reside en Bogotá. César, el sobrino, después de aprovechar ventajosamente el tardío florecimiento de los impulsos amorosos y maternales de su tía, la induce fácilmente a un matrimonio para el cual obtienen licencia eclesiástica. Poco después César se marcha con apreciable parte de la fortuna de su madura esposa, y no se vuelve a saber de él. A poco fallece Filomena.

La repugnante y cruel historia de la rapacidad de Filomena, de su retrasado despertar a las torturas del amor, de su ceguedad ante le bellaquería de César hasta que ya es demasiado tarde, se desenvttelve simultáneamente con otro aspecto del relato, no muy bien relacionado con el primero: la romántica historia sentimental de Pepa y Martín, manejada con sagaz habilidad y un delicioso sentido cómico.

Se dice que cuando apareció Frutos de mi tierra causó extraordinaria sensación en el restringido círculo antioqueño y que su realismo provocó las protestas del público lector. No sabemos que hubiera merecido igual acogida La Marquesa de Yolombó, publicada treinta y dos años después. Para muchos, ésta es aun superior a Frutos de mi tierra. Concordamos en que la obra es muy difusa y que habría resultado mejor estructurada con ser reducida siquiera a la mitad. Es un tesoro de cuadros de costumbres y de arcaísmos localistas. La trama se desenvuelve en los últimos años del período colonial, 1760-1825, época que Carrasquilla parece haber captado con máxima autenticidad. Bárbara, la protagonista, es una creación única en la novela latinoamericana. Gracias a una fortuna debida al hábil manejo de la mina de oro que le dió su padre, asciende de su juvenil inocencia y su absoluta ignorancia a una posición de respeto y autoridad en su comunidad. Cierta similitud con Frutos de mi ticrra se encuentra en el desgraciado matrimonio que contrae cuando 
ha dejado de ser joven, víctima de un habilidoso bribón que la abandona $\mathrm{y}$ del cual tampoco se vuelve a saber. Durante muchos años la tragedia obnubila la razón de Bárbara; se recupera en los últimos años y se convierte en un dechado de piedad. Su tragedia - tal nos llevan a creer los rumores circulantes en Yolombóse debió a una especie de brujería, que le fué enseñando su criada favorita, una negra.

Cronológicamente, y como novelista de categoría, sigue ese genio extravagante de José María Vargas Vila, cuya primera novela Aura o las violetas se publicó en Bogotá en 1892. Posteriormente editó sus obras en el exterior, en Barcelona, Madrid, París, Roma, La Habana y México. Esas publicaciones fuera de Colombia se debieron parcialmente al hecho de que Vargas Vila vivió en el exterior la mayor parte de su vida, como expatriado voltuntario; otra razón fué el hecho - fácilmente sospechable - de que sus novelas no encontraron editor colombiano, como que su contenido había sido deplorado por los pocos críticos nacionales que se han dignado comentar su arte. Parece que sus compatriotas lo hubiesen mirado con cierto recelo, como una especie de oveja negra literaria. Et comentario de Arango Ferrer es el más imparcial de cuantos hemos conocido de este escritor que "renegó de su tierra por pasión política, como si el concepto de patria dependiese de los hombres transitorios":

Vargas Vila, como novelista, tiene su clientela en el mundo camorrista y trasnochador que lee a Pedro Mata. Si la diatriba encarna en un valle de expiación, Vargas Vila resucitaría entre rayos y centellas ... posee una cataclísmica elocuencia y un poder satánico para falsear el concepto de los personajes, como sucede en Los Césares de la decadencia. Su espectro debe vivir asediado por la sombra de los presidentes que se sucedieron desde Núñez hasta Reyes, cuyas figuras se crispan en sus páginas como sangrientas máscaras. Poseía un lenguaje sibilino y era una especie de D'Annunzio calentano, pero ha sido el escritor nuestro más poptlar fuera de las fronteras. 25

Entre 1892 y el año de su muerte, 1933, Vargas Vila produjo más de sesenta volúmenes de prosa. En gran parte son ensayos o novelas cortas; cerca de unas dos docenas, novelas. Son novelas por lo menos si se amplía el término; un crítico se queja del anóma- 
lo contenido de algunos de los volúmenes que el autor, aparentemente, aspiró a que fuesen novelas. El huerto del silencio es ciertamente una novela, y Vargas Vila optó por escribirla como una "tragedia de amor" en cinco actos, aunque no para la escena. Si se atiende al carácter autobiográfico de otra "novela", Antes del último sueño - la serie de ensayos pretende ser un diario del autor después de cumplidos sus cincuenta años, Vargas Vila vivió en una deliberada soledad casi masoquística por razón de su lastimera autotortura. Tal parece que fué una de sus actitudes favoritas. Llama la atención como ningún novelista colombiano por su violenta posición iconoclasta en muchos campos. Declara -regustando la afirmación- que la sociedad existe sólo para que él pueda mofarse de sus más arraigadas convicciones. Desea haber sido Satán para haberse alzado contra Dios por su condenación al infierno.

Aparentemente, las almas tímidas evitan a Vargas Vila como un horrible caso de blasfemia. El lector más avezado puede analizarlo como ejemplo de una de las actitudes realmente extravagantes que el espíritu humano puede asumir en su demoledora busca de la emancipación de todo to convencional en materia de pensamiento $\mathrm{y}$ de vida.

Antes del último sueño fué escrito durante la estada del autor en Italia. Muchas de sus páginas aparecen matizadas aquí y allí con las críticas de Vargas Vila a sus propios críticos, y con sus esfuerzos por justificar sus estrambóticos actos e ideas. Llega casi a fastidiar al lector con su vanidad de autor, con sus burlas elementales, y la prueba de su casi patológica incapacidad de adecuación a la vida moderna. El huerto del silencio deja mejor impresión. Mantiene interesado al lector y aunque de argumento excesivo, extravagante e improbable, tiene méritos narrativos superiores a lo común. Vargas Vila conoce cabalmente los recursos del idioma, aunque algunos de sus críticos no aprueban la manera como los emplea.

El huerto del silencio se refiere a la apostasía de un clérigo, cuyas lecturas de los filósofos prohibidos y cuyas ideas sobre diversos asuntos, censuradas por sus superiores eclesiásticos, lo llevaron a la convicción de que Dios es Amor. Interpreta este concepto como la justificación de su afecto sensual por Clara, su joven prima. Ciegamente idílico durante algún tiempo, aquel amor culmina 
en el asesinato de ella por él cuando él se entera de que ella va a. ser madre; él no puede aceptar la paternidad por el temor de que su hijo herede la tara de la lepra que él heredó de su propio padre y que lo está corroyendo. El carácter notoriamente exagerado del relato exime de cualquier comentario. Pero no es posible ignorar la insólita capacidad de Vargas Vila para las narraciones patéticas, $\mathrm{y}$ es muy de desear un estudio minucioso de su arte como novelista. ${ }^{25 a}$

José Manuel Marroquín es una de las figuras más interesantes de la literatura colombiana. Presidente de la República, actuó en la literatura más afortunadamente que en la política. Aunque escribió otras novelas -Blas Gil (1896), Entre primos (1897) y Amores y leyes (1898) - su obra maestra, según el criterio general, es $E l$ moro, ${ }^{26}$ una especie de Black Beauty en español, pero mejor escrita que nuestra clásica novela equina. Moro, el protagonista, es un caballo cuyas andanzas cubren gran parte de la sabana de Bogotá, y cuya sagaz observación de la naturaleza humana y sus fragilidades lo mismo que de las costumbres de su provincia natal constituyen un amenísimo relato. Moro conoce a muchos caballos y a no pocas personas interesantes y su descenso, en la escala social equina, de la condición de animal de silla a la de animal de tiro, es relatado con melancólica singularidad.

En los diez años corridos entre la aparición de El moro y de la novela que inmediatamente recibió los mayores elogios de la crítica, se publicaron algunas novelas que conviene mencionar. Samuel Velásquez, un antioqueño, se distinguió como admirable pintor de costumbres regionales con sus novelas Al pie del Ruiz (1898), Hija (1904) y Madre (1908), esta última ganándole -entre cincuenta y ocho opositores- el primer premio en un concurso de novelas colombianas patrocinado por La miscelánea de Medellín. Daniel Bayona Posada y Pedro Gómez Corena colaboraron bajo el seudónimo de Rodrigo de Rahavánez para producir Contrastes (1905) y Caprichos (1907), novelas que responden al género costumbrista. Años después, Gómez Corena volvió a explotar la misma vena en su obra Cizaña (1921). Marco Antonio Jaramillo escribió Mercedes en 1907, calificada por Tomás Carrasquilla de la mejor novela de Colombia después de Maria. ${ }^{27}$ Es lamentable que obra tan destacada sea de hallazgo sumamente difícil ; no existe ejemplar en ninguna de las colecciones particulares ni públicas que hemos explorado. 
En 1907, Lorenzo Marroquín, hijo de don José Manuel, terminó y publicó una revisión de su $P a x$, que había empezado en colaboración con José María Rivas Groot, autor éste de la preciosa novelita Resurrección (1901), y la premiada El triunfo de la vida (1916). Como novela de clave y de costumbres latinoamericanas, la aparición de Pax suscitó un tremendo revuelo. Para el lector moderno no tiene el mismo interés, por razones obvias, a lo cual se agrega que la lentitud de su desarrollo la hace menos atractiva. Para el extranjero en general ha de ser una obra bastante pesada. Es, sin embargo, un valioso documento del costumbrismo; y el fervor, gran sinceridad $\mathrm{y}$ alto idealismo de su autor revelan una personalidad muy atractiva. Es muy eloctente como catilinaria contra la guerra civil; como novela, tiene grandes defectos de índole fundamental, particularmente de estructura y presentación de personajes. Resulta de sumo interés para los modernos estudiosos de la poesía hispanoamericana saber que ese extravagante poeta Mata, tan ásperamente delineado, es, probablemente, una caricatura de José Asunción Silva. En el capítulo octavo de la novela aparece una extensa parodia del famoso "Tercer nocturno."

A medida que nos aproximamos a la tercera década del siglo, pensamos en La vorágine, cuya primera edición apareció en 1924. Sería injusticia, sin embargo, pasar por alto a unas novelas, aparecidas anies del ya clásico libro de Rivera, que los críticos han tratado con generosa benevolencia. Diana cazadora de Clímaco Soto Borda salió en 1915. Esta novela sobre la vida de Bogotá, "humana como pocas," ha sido encomiada por su fantasía, su belleza idiomática y la firmeza y realismo de sus personajes. Encomiadas también han sido Sangre conquistadora (1911) y Uno de los catorce mil (1922), novelas del antioqueño Roberto Botero Saldarriaga. Uno de los catorce mil resulta inferior en conjunto, como que le falta en grado desconcertante continuidad narrativa, aunque en sus mejores páginas y atn en capitulos enteros la lectura sea muy agradable. Describe francamente, pero con discreción de lenguaje, el clericalismo de Colombia que ocasionalmente ha llevado a la guerra civil. Aunque pinta una guerra librada casi medio siglo antes de que se escribiera la novela, su mensaje en favor de una Colombia unida conserva cierta actualidad. Aparentemente, varios personajes son gente real. Se reconoce a José María Samper, aunque se le menciona sólo de 
paso, y también a Parra, un liberal elegido presidente en 1876, a raíz de la sangrienta guerra civil descrita en la novela. Las novelas cortas, La ráfaga (1910), Lilí (1923), y La selva oscura (¿ 1924 ?), de Emilio Cuervo Márquez, todas bien logradas, demuestran que la vida social de Bogotá, aunque pobre en aspectos, "le of rece al novelista un campo suficientemente vasto para explayar su observación." 28

La vorágine de Rivera señala una época en la novela colombiana. La obra es demasiado conocida para que haya necesidad de describirla en estas páginas. ${ }^{29} \mathrm{E} 1$ año de su publicación (1924) no marca en modo alguno el fin de la producción novelística en Colombia. Por el contrario: el género continúa floreciendo y cobrando estatura. Luis López de Mesa escribió La tragedia de Nilse (1928) y La biografia de Gloria Etzel (1929), ambas elogiadas por Ortega. Arturo Suárez siguió publicando más novelas, pero éstas no pueden rivalizar en popularidad con las anteriores, Montañera (1916), El alma del pasado (1921), Rosalba (2 ed., 1924), y Así somos las mujeres (1928), que alcanzaron, en el caso de Rosalba, hasta diez ediciones agotadas. De unas cinco compuestas por Daniel Samper Ortega, Zoraya (1931) es generalmente considerada como la mejor. Es aceptable por su evocación de la España y la Colombia de hace algún tiempo, aunque algunas de sus páginas son poco más que una genealogía. Pero en conjunto, la novela es inferior. Refiere la historia de un virrey de la Nueva Granada en el siglo xvirI, don José Solía, y sus amores con María Lugarda de Ospina. María, arrepentida, toma el velo; don José, desilusionado con el tedio de la existencia y sinceramente arrepentido ingresa a la orden franciscana. César Uribe Piedrahita escribió Toá, ${ }^{30}$ no mal lograda, pero inferior a $L a$ vorágine, a la que imita. El mismo autor escribió Mancha de aceite (1935), que Arango Ferrer describe como una "novela de petroleras venezolanas, con una tesis anti-imperialista insinuada ..." Arango llega a decir de Uribe Piedrahita que "es un hombre en ascuas ardido de inquietudes: médico, arqueólogo, dibujante y finalmente novelista de grandes posibilidades." Arango puede sentir por él cierta afinidad espiritual debido al hecho de que ambos son médicos.

José Antonio Osorio Lizarazo ha escrito por lo menos una novela que ha merecido el elogio de un crítico tan autorizado como 
Mariano Latorre. Para Latorre La cosecha (1935) es novela pura y real en el sentido de Thérive, por cuanto posee vida y acción, y sus personajes viven por sí mismos sin necesidad de técnica deslumbrante, de estilo ampuloso o de alardes psicológicos. Su autor tiene esa cualidad primordial del novelista que es el equilibrio, la armonía de la composición. El poeta, el paisajista, el estilista, todos son uno, y ninguno sobresale inadecuadamente. En este aspecto - considera Latorre- Osorio Lizarazo sobrepuja a Rivera y a casi todos los actuales novelistas de la América del Sur. Sólo Güiraldes, Azuela, y en menor proporción Rómulo Gallegos, tienen las dotes de Osorio Lizarazo. La cosecha describe la vida de un cafetal. Los personajes de la novela tienen un desenfrenado primitivismo de índole trágica, desconocido en Chile, afirma Latorre. Osorio Lizarazo afronta el problema social de la vida campesina colombiana, y sin embargo no hace propaganda; Latorre deplora la actual tenencia de la novela social, en la que el sociólogo se antepone al novelista. ${ }^{31}$

Se estima a Gregorio Sánchez Gómez, autor de unas diez novelas de distintos tipos — psicológico, evocativo, de costumbres-.-, y de otras tantas novelas cortas, como uno de los mejores novelistas contemporáneos. Merecen mención aparte su novela de la vida social moderna, Rosario Benavides, laureada por la Academia Colombiana, y su relato de fantasía y humorismo, La vida de un muerto que, según Arango Ferrer, coloca al autor entre "los buenos humoristas con que cuenta América." Barrancabermeja (1934) de Rafael Jaramillo Arango, aunque discretamente elogiada por los críticos, le deja a uno defraudado: ni siquiera el tema anti-estadiense "cuaja." Ortega califica la novela de pornográfica. Es, ciertamente, franca, pero los lectores habituados al realismo de la novela contemporánea no tienen por qué extrañarse en tal sentido. El autor la denomina una "novela de rufianes, proxenetas, obreros y petroleros," y en sus ochenta y seis páginas encierra un mensaje social en que se deploran las arduas condiciones en que viven los obreros de las refinerías de petróleo. La técnica estructural es parecida a la de una película de hace tiempo, por su esporádico y episódico movimiento.

Novelas altamente encomiadas han sido Cuatro años a bordo de mi mismo (1934) de Eduardo Zalamea Borda, que, aunque calificada de pornográfica por Ortega, “... está reputada,” según 
Arango Ferrer, "como uno de los más acertados esfuerzos ... por crear la novela nacional," y Una derrota sin batalla (1933) de Enrique Pardo Farelo (Luis Tablanca), una sátira violenta de la política colombiana contemporánea, que debe de ser aclamada como una de las mejores novelas escritas en Colombia en los últimos años. Tiene esta última una cualidad que es raro encontrar en una novela hispanoamericana: una estructura adecuada. El relato es sostenido; lo mismo que la caracterización; la propaganda es lo suficientemente discreta para resultar aceptable; el idealismo reformista del autor es digno y en ningún momento histérico. Uno de sus más notables elementos es el humor sardónico. La acción se desarrolla en 1930, año en que los liberales tomaron el control de la política colombiana. El protagonista, un individuo tan idealista como ingenuo, y que desconoce tanto la naturaleza humana como la política práctica, es llamado de su retiro rural a la secretaría de gobierno del departamento, cuyo ejecutivo preside un viejo amigo suyo. El relato se refiere a la progresiva desilusión de los dos idealistas durante un régimen de sólo cinco días; al expirar ese lapso ambos renuncian, incapaces de hacer frente a los políticos profesionales que los rodean. Todos esos políticos son inescrupulosos y solapados; lo son, en parte, porque el pueblo colombiano, según la novela, espera que los servidores públicos procedan en esa forma.

Una novela que rebasa el nivel común es Ayer, nada más (1930) de Antonio Alvarez Lleras. Altamente elogiada por Ortega, resulta interesante aunque desigual. Tiene una acción considerable y una caracterización mejor que la ordinaria. Es uno de los raros casos en que un novelista colombiano intente un estudio psicológico. E1 protagonista, Mariano Mendizábal, es un personaje complejo, una mezcla de fuerza y de gran debilidad. Su mayor defecto es la falta de voluntad, consecuencia de su ascendencia española, si es que Angel Ganivet está en lo cierto cuando insiste en que la abulia es la gran falla del carácter español peninsular. Ocasionalmente el autor se muestra perpicaz; otras veces sus observaciones son perfectos lugares comunes. La novela encierra una lección moral: que todos somos libres para escoger entre el bien y el mal, y que no podemos culpar al medio de nuestros fracasos.

Bernardo Arias Trujillo cuenta en su haber solamente una novela, pero ésta es seguramente una de las tres o cuatro mejores que 
han aparecido en Colombia en este siglo. La novela es Risaralda; su año de publicación 1935. La muerte prematura del joven autor a los treinta y cuatro años interrumpió una de las más prometedoras carreras literarias. El autor califica su novela de "película de negredumbre y de vaquería filmada en dos rollos y en lengua castellana." Por eso la obra está dividida en dos partes; una relativa a los orígenes del pueblo de Portobelo, y otra a la época moderna, que concluyó hacia 1915. Portobelo, situado en la confluencia de los ríos Risaralda y Cauca, fué primitivamente poblado por esclavos negros libertos, y gran parte de la obra equivale a un rico acervo de dialecto negro. La colonización de Portobelo y la subsiguiente vida cívica constituyen la mayor parte del argumento de la obra; el campo circunvecino ofrece cuadros de la vida de vaquería mencionada en el subtítulo. Hay mucho costumbrismo, mucha poesía popular. El relato se ajusta a la moderna tendencia realista, que en ocasiones se acerca a la pornografía, pero que no resulta ofensiva del gusto contemporáneo. En él se encuentra la mejor descripción del exótico y lascivo baile negro después de la de Carlton Beals en Cuba Libre. Como la mayoría de las novelas hispanoamericanas, Risaralda falla a veces en su fuerza narrativa y es posible también que el lector encuentre ciertos pasajes excesivamente brutales. Pero la caracterización es persuasiva, el estilo poético y muy hermoso; un vigor primitivo anima todo el conjunto y la acción es patética. El resultado es una obra excepcional en la novelística colombiana.

Habrá que mencionar algunos novelas más de los últimos años, no porque pasen de ser más que de regulares a buenas sino porque servirán como ejemplos de la creciente experimentación en distintos tipos del género que caracteriza el cultivo de la novela hoy día en Colombia. Roque, La novela de los tres, y David, hijo de Palestina, novelas de José Restrepo Jaramillo escritas después de 1925, se encuentran entre las primeras del tipo psicológico en el país. Los de en medio (1938) de Augusto Morales Pino es una novela de la ciudad: la pequeña miseria y el horizonte desesperadamente restringido de la clase media urbana aparecen con toda su trágica intensidad y aunque en conjunto la novela es regular, tiene momentos excelentes. La psicología del sensitivo adolescente está descrita con cierta habilidad: El infierno azul (1939) de Vicente Noguera Corredor representa la novela sensacional. Relato fantástico de una incursión 
por el mundo de los drogómanos de París hacia el año 20, hay en ella poco que recomendar al lector impaciente. Tipacoque (1941) de Eduardo Caballero Calderón, ensalzada por Arango Ferrer y Luis Durand, es de la mejor tradición costumbrista. $\mathrm{Y}$, finalmente, la novela indianista y de protesta social tiene digno discípulo en el joven novelista popayanés Diego Castrillón Arboleda, autor de José Tombé (1942) y Sol en Tambalimbú (1949).

\section{Conclusión}

Este breve bosquejo de la novela colombiana se ha referido únicamente a unos pocos de los numerosos escritores que han cultivado el género a partir del año de 1836. Sin embargo, se ha tratado de escoger a los que mejor representan la novelística colombiana. Muchos de esos escritores han publicado sólo una novela: en un país cuyo público lector es pequeño, el artista literario debe atender a su subsistencia mediante alguna actividad remuneradora, y novelas largas no se producen con frecuencia cuando hay que escribirlas en los momentos libres. Vargas Vila, el más prolífico de los novelistas colombianos, vivió en el exterior, presumiblemente de alguna renta independiente.

Se han ensayado casi todos los tipos de novelas. Hay novelas de la ciudad (Ayer, nada más y Frutos de mi tierra, por ejemplo); novelas del campo (Risaralda, María, Manuela) y de la selva ( $L a$ vorágine, Toá). Hay novelas de la mina, tal como La marquesa de Yolombó; de los blancos y los negros o los mulatos (las novelas de Carrasquilla, Risaralda, Sol en Tambalimbú); del trabajar petrolero (Barrancabermeja) y del vaquero (Risaralda).

La novela colombiana ha seguido las modas literarias. Maria y $E l$ alférez real, por ejemplo, son eminentemente románticas. $M a$ nuela y casi todas sus sucesoras son costumbristas y realistas. La vorágine reactualizó en Colombia la novela contemporánea de sabor realista, y desde entonces la mayoría de las novelas han seguido la tendencia de Rivera, en lo que se refiere a la busca de tema en el ambiente y en el tratamiento realista de aquél. Acabamos de ver no hace mucho que los novelistas colombianos han ensayado la novela psicológica. También ha aparecido, la novela de intención social: 
Los de en medio, Barrancabermeja, Luchas sociales. No se ha desdeñado la lucha contra la guerra civil: Pax, Uno de los catorce mil. Ni contra la corrupción política (Una derrota sin batalla, Sol en Tambalimbú). Cultivada dispersamente en los comienzos de su historia, la novela ha aumentado en número y estatura, y constituye hoy un género del ctal los colombianos pueden estar orgullosos. ${ }^{32}$ En escritos de 1942, Nicolás Bayona Posada declara que la novela de su país no es hoy "un tejido de fantasías, sino tela formada con hilos arrancados al telar de la vida ... Amplio sentido social, estudio del alma colectiva, análisis concienzudo del documento humano: eso es lo que el público solicita de los escritores, y. eso lo que ha traído como consecuencia ineludible el que los escritores -al infundirles el mismo espíritu - hermanen más cada día la historia, la novela y el teatro. Ante una buena novela de los últimos años, o ante una pieza teatral de corte nuevo, nadie se siente ya llevado a un mundo imaginario, sino viviendo una página de historia humana, más verdadera muchas veces que la apoyada en documentos."

Gerald E. Wade, University of Tennessee.

John E. EngLeKirk, Tulane University.

\section{$\mathrm{NOTAS}$}

1. Roberto Cortázar, La novela en Colombia. Tesis doctoral. Bogotá, Imp. Eléctrica, 1908, vIII + 112 + vI. La obra consta de cinco capítulos, que son: I. Novelas más o menos realistas y de costumbres; II. Novelas históricas; III. La María como perteneciente a un grupo aparte por contener en sí muchos géneros literarios; IV. La novela antioqueña, que difiere de las demás y que tiene caracteres propios; y V. Novelistas más recientes. Según Javier Arango Ferrer (La literatura de Colombia, Buenos Aires, "Coni", 1940, 19), Jorge Rodríguez Páramo hizo un estudio de la novela que está aún inédito. No hemos podido comprobar la existencia de tal manuscrito.

2. Bogotá, Edit. Minerva, 1937. Cien volúmenes. Esta célebre colección de literatura colombiana, patrocinada por el Ministetio de Educación, fué promovida y dirigida por el distinguido crítico y escritor, Daniel Samper 
Ortega. A veces se refiere a ella todavía como la Biblioteca Aldeana de Colombia.

3. 2 ed., 1935. De 1214 páginas grandes, el tomo es tanto una antología como una historia. Es difícil de usar, porque la materia sobre la novela queda esparcida por todo el volumen. Como bibliografía, es incompleta y carece a veces de precisión. Es deficiente en la omisión de algunos novelistas y de indispensables detalles bibliográficos relativos a fecha, lugar de publicación, edición y casa editorial. A menudo confunde la novela con el cuento. El criterio estrechamente ortodoxo del autor reduce en mucho, a veces, el valor de su crítica y aprecio de una obra.

4. 5 ed., Bogotá, Edit. Voluntad, 1945, 225-249.

5. Bogotá, Eds. Samper Ortega, 1942, 89-98.

6. 4 ed,, Bilbao, El Mensajero del Corazón de Jesús, 1933. E1 autor critica más de tres mil novelistas de muchos países.

7. México, Fondo de Cultura Económica, 1944, 213.

8. Bogotá, Imp. Nacional, 1945-1946, 4 v. Hay varios estudios cuyos títulos nos darían a esperar algo sobre la novela colombiana; lo que nos ofrecen es bien poco, o nada, como se verá en el caso de los que aquí citamos: Diego Rafael de Guzmán, De la novela: Sus origenes y desenvolvimiento (Bogotá, Edit. Minerva, 1935, 170. SSO : 5). Dictado como curso en 1883, ocupa sólo las páginas 17-110; las restantes contienen otro discurso del autor -fechado el 6 de agosto de 1877- intitulado "Importancia del espíritu español en las letras colombianas." De la novela es una breve exposición de la novela mundial, inclusive la de España; no trata de la novela colombiana ni hispanoamericana; Juan José Molina, Ensayos de literatura y de moral (Primera serie. Medellín, Imp. Republicana, 1886, vrr + 394). Contiene un capítulo sobre "La novela," páginas 295-320, en que el autor da un repaso general de los distintos tipos del género, con ejemplos y crítica de la novela moderna, principalmente la de Francia, Inglaterra y España. Con respecto al cultivo de la novela en Colombia, escribe: "Es verdad, pero también es de notarse que todo lo que posee Colombia sobre novelas es apenas un ensayo incompleto $y$ muy reducido, que aún no ha formado ni pretendido formar escuela. Los Pizarros de Felipe Pérez, María de Jorge Isaacs, El Doctor Temis de Angel Gaitán, Martín Flórez de Samper, Manuela de Eugenio Díaz, Olivos y aceitunas de Vergara y Vergara, Teresa de doña Soledad Acosta de Samper, Travesuras de un tunante, de Rozo, Don Alvaro de C. Rojas, El Siglo XIX de Madiedo, Los embozados de Torres Torrente, y otras pocas ni han tenido la resonancia suficiente, ni han calado en las masas para agitarlas e imprimir determinación a los espíritus. Su estudio no sería de una utilidad práctica por la faz por la cual (la moral y la literattura) miro el asunto"; Arcesio Aragón, La novela (Varios cuadernos, Bogotá, Biblioteca Nacional, s. f.). Es un discurso académico, dictado el 30 de junio de 1895 en la Universidad del Cauca, sobre la novela mundial desde sus orígenes hasta 1895 . Termina con algunas observaciones sobre la novela 
colombiana, refiriéndose a María y a Manuela como "dos joyas de acabada ejecución y riquísima ley"; Roberto Arrazola. Sesenta plumas escriben para Ud. (Buenos Aires, Edit. Colombia, s. f. [1944], 674. Prólogo y notas). Una antología de la prosa colombiana, incluye selecciones de un número considerable de novelistas. con datos bio-bibliográficos.

9. Atenea (Concepción, Chile), xxxIv, 131, mayo, 1936, 154-167.

10. Quito, Talleres Gráficos de Educación, 1937, 21.

11. Revista de la Universidad del Cauca, 9, junio, 1946, 1-31; véase también Atenea, Lxxxirr, 248, 200-235.

12. A literatura hispano-americana no Brasil: 1877-1944. Baton Rouge, Louisiana State University Press, 1948, 54-57.

13. Véase: Sturgis E. Leavitt, Hispano-American Literature in the United States. Cambridge, Harvard University Press, 1932, x + 54; ibid., 1932-1934, Chapel Hill, The University of North Carolina Press, 1935, 21; Sturgis E. Leavitt, "A Bibliography of Theses Dealing with Hispano-American Literature," Hispania, xviII, 1935, 169-182, y anualmente después; y Willis Knapp Jones, Latin American Writers in English Translation. Washington, D. C., Pan American Union Bibliographic Series, N 30, 1944.

14. V. 1. Bogotá, Imp. Medardo Rivas, 1895, 296. De Miguel Abadía Méndez a Esteban Ovalle, inclusive.

15. Bogotá, "El Espectador," 1925, 329.

16. 3 v. Bogotá, 1927-1939; v. I. Cromos, 1927, 828. A-F; v. II. Edit. Aguila, 1937, 836. G-M; v. III. Edit. Aguila, 1939, 1026. M-Z.

17. Bogotá, Edit. Minerva, 1928, 292.

18. Bogotá, Edit. Minerva, 1928, 272.

19. Cambridge, Harvard University Press, 1934, 80.

20. Cambridge, Harvard University Press, 1935-1945. 11 v.

21. New Haven, Yale University Press, 1939, $x+335$.

22. 2 ed. Bogotá, Edit. Kelley, 1948, xv + 540.

23. "Soledad Acosta de Samper", Boletin de historia y antigüedades (Bogotá), XXIv, 271, mayo, 1937, 266.

24. La literatura de Antioquia, un departamento al noroeste de Bogotá, en los Andes, es una joya espléndida de la literatura colombiana. Su estudio definitivo no ha sido escrito hasta ahora. La novela antioqueña (México, Imprenta "Vizcaya," 1942) de Enrique C. de la Casa, conjunto de datos mal organizados de otras fuentes ya conocidas, no nos ofrece nada nuevo ni original. Quizás sea el periodismo literario de la región una de las mejores fuen- 
tes para un estudio serio y autorizado de las letras antioqueñas. Para citar sólo un caso, véase, por ejemplo, la excelente revista ilustrada de literatura, artes y ciencias El montañés de Medellín, redactada por Gabriel Latorre, que apareció en septiembre de 1899 y salía mensualmente por cosa de dos años. Una lista de los mejores novelistas de Antioquia incluye, además de Carrasqui1la, a los siguientes: Samuel Velásquez, Eduardo Zuleta, Francisco de Paula Rendón, Gabriel Latorre, Alfonso Castro, Efe Gómez (mejor conocido como cuentista), Roberto Botero Saldarriaga, y José Restrepo Jaramillo. Los más de los nombres citados recibirán mención más abajo.

25. Acaso más que ningún otro literato colombiano, Vargas Vila pudo exaltar a algunos de sus compatriotas a los más desorbitados insultos. Ladrón de Guevara, por ejemplo, escribió de él: "Sentimos verdaderamente que sea de esta cristiana república este señor, de quien nos vemos precisados a decir que es un impío furibundo, desbocado blasfemo, desvergonzado calumniador, escritor deshonesto, clerófobo, hipócrita tenazmente empeñado en que lo compren por recto, sincero y amante de la verdad; egoísta con pretensiones de filántropo, $\mathrm{y}$, finalmente, pedante, estrafalario hasta la locura, alardeando de poligloto con impertinentes citas de lenguas extranjeras; inventor de palabras estrambóticas, y, en algunas de sus obras, de una puntuación y una ortografía en parte propias de perezosos e ignorantes; aunque, en honor a la verdad, él no la usa porque no sepa bien esa parte de la gramática, sino por hacerse singular. Sin embargo, no se le tenga por tan singular, pues hay autor italiano, impiísimo también, y repugnante, con el cual en el estilo, lenguaje, impiedad e inmoralidad, coincide no poco el señor Vargas Vila." E1 "autor italiano" es, desde luego, D’Annunzio.

25a. Alejandro Andrade Coello ofrece una síntesis bastante aceptable del arte de Vargas Vila hasta el año 1912; véase su Vargas Vila. Ojeada crítica de sus obras. Quito, 1912.

26. En el mismo año de El moro, 1897, apareció en Medellín Tierra virgen, de Eduardo Zuleta. Esta obra ha sido elogiada más de lo que merece. Como relato conjunto, es flojo y desarticulado. Como sucesión más o menos inconexa de cuadros de costumbres, tiene algún mérito. Pinta la vida de Remedios, una población de Antioquia. Su apasionante dialecto negro se aparta del castellano ordinario aun más que el de las novelas de Tomás Carrasquilla.

27. Ortega, ob. cit., 508.

28. Eduardo Castillo, Cromos (Bogotá), xxi, 503, 24 de abril, 1926.

29. Véase: Arturo Torres-Ríoseco, Novelistas contemporáneos de América. Santiago, Nascimento, 1939, 45-90; Eduardo Neale-Silva, "The factual bases of La vorágine," PMLA, LIv (1939), 316-331; y Jefferson Rea Spell, Contemporary Spanish-American Fiction, Chapel Hill, The University of North Carolina Press, 1944, 179-190. Mariano Latorre insiste en que Rivera realmente nada inventó fundamentalmente de nuevo en la novela; que imitó la técnica de Tomás Carrasquilla (y de Blest Gana en Chile). La originalidad 
de Rivera consistió en el uso del tema de la selva, un tema que Carrasquilla no había descubierto.

30. Según el autor, toá es la palabra india por 'candela.' Toá es una mestiza de quien se enamora el protagonista, don Antonio. Ella muere al dar a luz a su niño, que también muere. La novela termina con Antonio muy enfermo, debilitado hasta la muerte por las fiebres que la selva le ha dado.

31. De Osorio Lizarazo se ha escrito un buen estudio de fecha reciente. Véase: Charles N. Staubach, "The Novels of J. A. Osorio Lizarazo," Hispania, xxxII, (1949), 172-180.

32. Ortega, quien nira hacia atrás nostálgicamente, dice que los novelistas contemporáneos por lo general siguen a los maestros de la centuria pasada, y que es una lástima que el naturalismo quite su mérito a muchas novelas que en ciertos sentidos son buenas. Deplora la influencia de los modelos extranjeros que, en su opinión, están llevando a los escritorés colombianos en dirección contraria a los cuadros de costumbres y la novela regionalista. 
